\title{
PHOTO-ESR AND ABSORPTION STUDIES OF ANTISITE DEFECTS IN GaP*
}

\author{
M. PALCZEWSKa \\ Institute of Electronic Materials Technology, Wólczyńska 133, 01-919 Warszawa, Poland \\ J. JASIŃSKI AND M. KAMIŃSKA \\ Institute of Experimental Physics, Warsaw University \\ Hoża 69, 00-681 Warszawa, Poland
}

\begin{abstract}
Photo-ESR and optical absorption measurements were done on annealed neutron irradiated GaP crystals. The position of paramagnetic gallium antisite level in $\mathrm{GaP}$ energy gap has been determined. Additionally, the position of paramagnetic phosphorus antisite level, earlier determined in the paper of Kruger and Alexander, has been confirmed. Moreover, unusual in ESR experiments temperature dependence of phosphorus antisite amplitude in neutron irradiated $\mathrm{GaP}$ crystals has been explained.
\end{abstract}

PACS numbers: 71.55.Eq, 78.50.Ge, 76.30.Mi

Anion antisite defects are fundamental native defects of III-V semiconductors. They are present in as grown crystals, especially in $\mathrm{GaAs}$ and $\mathrm{GaP}$, and can also be introduced by plastic deformation, electron or neutron irradiation and ion implantation. ESR measurements proved that phosphorus antisite defects $\mathrm{P}_{\mathrm{Ga}}$ in $\mathrm{GaP}$ introduced by n-irradiation were exactly the same as in as grown crystals, i.e. they consisted of central phosphorus atom surrounded by four phosphorus ligands, $\mathrm{P}_{\mathrm{Ga}} \mathrm{P}_{4}$ [1]. However, very little is known about cation antisite defects in III-V semiconducting materials. In particular, none of cation antisite defects has been found in as grown crystals. On the other hand, the ESR spectrum observed in plastically deformed $\mathrm{GaP}$ and GaAs crystals were attributed to the gallium antisite, Gap, probably as a part of a complex defect [2].

Our previous ESR studies revealed that mainly two defects were created during n-irradiation of $\mathrm{GaP}$ crystals: phosphorus antisite $\left(\mathrm{P}_{\mathrm{Ga}}\right)$ and the defect labelled WA1 $[1,3]$. ESR spectrum of WA1 and its angular dependence were very similar to what was observed in plastically deformed $\mathrm{GaP}$ and $\mathrm{GaAs}$ and attributed to gallium antisite defect [2]. Such identification is consistent with our observation of similarity of WA1 defect introduction rate during n-irradiation [1] as well as its

*This work is supported in part by the State Committee for Scientific Research (Republic of Poland) grant No. 3P 40702506. 
post-irradiation annealing behavior [3] in comparison with other antisite defects: $\mathrm{P}_{\mathrm{Ga}}$ in $\mathrm{GaP}$ [3] and $\mathrm{As}_{\mathrm{Ga}}$ in GaAs crystals [4].

In the presented paper detailed photo-ESR and absorption studies of post-irradiated annealed GaP crystals were performed mainly in order to get information about properties of cation antisite defect, especially its energy levels within GaP energy gap.

The investigated samples were cut from phosphorus rich GaP crystals grown by liquid encapsulated Czochralski method and irradiated with fast neutrons of $3.7 \times 10^{17} \mathrm{~cm}^{-2}$ dose in the Maria core at Świerk. Annealing was performed under phosphorus overpressure in the temperature range $300-650^{\circ} \mathrm{C}$. As irradiated crystals had very high absorption coefficient, above $100 \mathrm{~cm}^{-1}$ in the energy range below band to band transitions. This absorption decreased with annealing. Samples annealed in temperature above $600^{\circ} \mathrm{C}$ showed absorption coefficient low enough that photo-ESR and absorption studies were possible.

The paramagnetic energy level of antisite phosphorus $\mathrm{P}_{\mathrm{Ga}}^{+/++}$in $\mathrm{GaP}$ has been determined by Kaufmann et al. [5] as $1.25 \mathrm{eV}$ above GaP valence band. Observed spectral dependence of ESR signal intensity of $\mathrm{P}_{\mathrm{Ga}} \mathrm{P}_{4}$ in neutron irradiated $\mathrm{GaP}$ (Fig. 1a) confirmed such determination. Decrease in ESR intensity of $\mathrm{P}_{\mathrm{Ga}} \mathrm{P}_{4}$
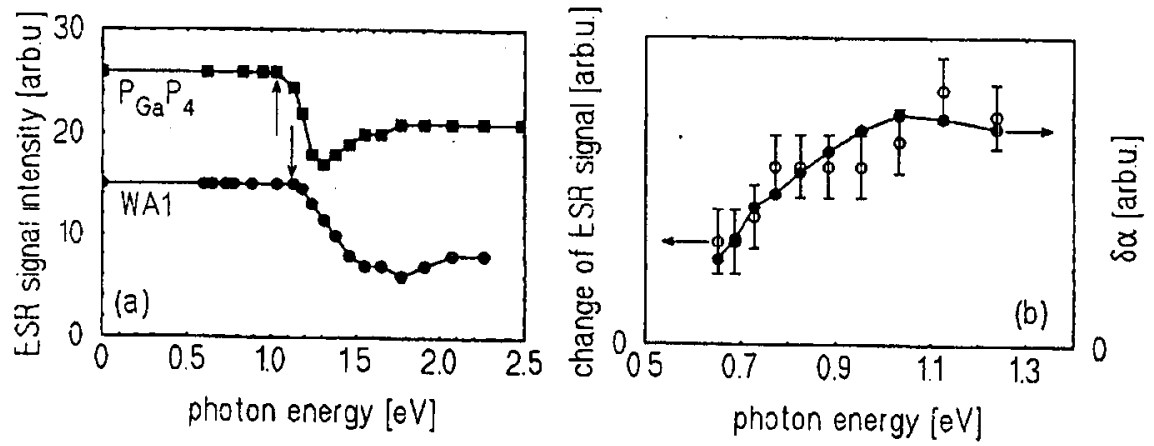

Fig. 1. (a) Spectral dependencies of ESR intensities of $\mathrm{P}_{\mathrm{Ga}} \mathrm{P}_{4}$ and WA1 signals for n-irradiated $\mathrm{GaP}$ crystals annealed at $650^{\circ} \mathrm{C}$. (b) Spectral dependencies of changes in ESR signal intensity of WA1 defect $(\circ)$ and absorption coefficient at $1.6 \mu \mathrm{m}(\bullet)$ measured after previous illumination with $1.75 \mathrm{eV}$ light energy in n-irradiated GaP crystals annealed at $650^{\circ} \mathrm{C}$.

signal starting at about $1.1 \mathrm{eV}$ energy of illuminating light could be attributed to electron transition from the paramagnetic $\mathrm{P}_{\mathrm{Ga}}^{+/++}$level to the conduction band. Moreover, electron transition from the valence band to the paramagnetic $\mathrm{P}_{\mathrm{Ga}}^{+/++}$ level could also occur for the light energy above $1.25 \mathrm{eV}$. These two processes lead to saturation of $\mathrm{P}_{\mathrm{Ga}} \mathrm{P}_{4}$ signal above $1.6 \mathrm{eV}$ (Fig. 1a).

ESR intensity of WA1 signal remained unchanged up to $1.2 \mathrm{eV}$ energy (Fig. 1a). Decrease in WA1 intensity starting at about $1.2 \mathrm{eV}$ energy of illuminating light allowed to determine the position of WA1 paramagnetic level as $1.2 \mathrm{eV}$ below the conduction band. WA1 intensity reached minimum value at about 
$1.75 \mathrm{eV}$ energy. This signal (obtained after illumination with light of $1.75 \mathrm{eV}$ energy) was further investigated when additional illumination of sample was applied. The change of its amplitude as a function of light energy corresponding to additional illumination is presented in Fig. 1b. As seen, WA1 amplitude observed after illumination with $1.75 \mathrm{eV}$ could be increased when additional illumination with light from energy range $0.5-1.2 \mathrm{eV}$ was provided. Similarly, absorption coefficient of the sample at $1.75 \mathrm{eV}$ energy could be changed when additional illumination with the light of lower energy, below $1.2 \mathrm{eV}$ was applied (see Fig. 1b). Spectral dependence of light induced changes of both ESR signal and absorption coefficient obtained for $1.75 \mathrm{eV}$ energy light are very similar as seen from Fig. 1b and have their threshold at above $0.5 \mathrm{eV}$.

One of probable interpretations of the results described above is assumption that there is a defect with energy level about $0.5 \mathrm{eV}$ below GaP conduction band (see Fig. 2a). As will be shown below, the Fermi level is placed around midgap in the investigated samples. Therefore, illumination with $1.75 \mathrm{eV}$ light causes electron transitions from $\mathrm{Ga}_{\mathrm{P}}^{-10}$ to the conduction band. Some of these electrons can be

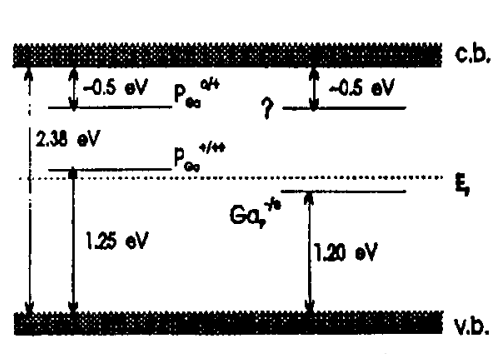

(a)

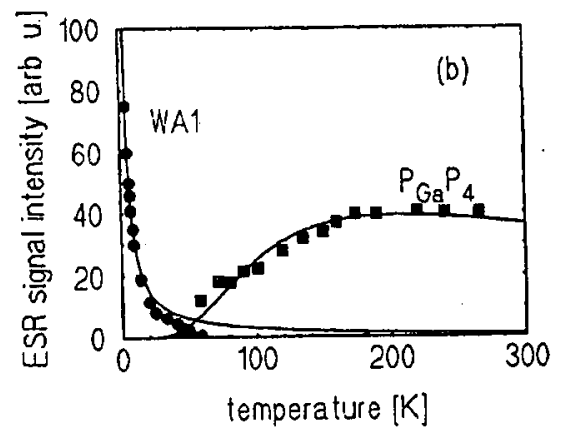

Fig. 2. (a) Positions of $P_{G a}$ and GaP defect levels in GaP energy gap. (b) Experimental results and fitted curves $\left(E_{\mathrm{F}}=1.229 \mathrm{eV}\right)$ for temperature dependencies of WA1 and $\mathrm{P}_{\mathrm{Ga}}$ ESR amplitudes in n-irradiated $\mathrm{GaP}$ crystals.

trapped at the proposed defect placed $0.5 \mathrm{eV}$ below $\mathrm{GaP}$ conduction band. Release of these electrons with light starting from $0.5 \mathrm{eV}$ may lead to increase in WA1 occupation. There is some probability that $0.5 \mathrm{eV}$ level belongs to Gap defect, being its $\mathrm{Ga}_{\mathrm{P}}^{--1-}$ charge state. It is also possible that energy level of another component (not Gap) of WA1 complex defect is placed at $0.5 \mathrm{eV}$ below GaP conduction band.

Our previous ESR studies of n-irradiated GaP crystals revealed unusual temperature behavior of $\mathrm{P}_{\mathrm{Ga}} \mathrm{P}_{4}$ signal $[1,3]$. The intensity of $\mathrm{P}_{\mathrm{Ga}} \mathrm{P}_{4}$ line for n-irradiated samples increased with temperature increase, whereas typically ESR lines decrease with increasing temperature. It was checked that this behavior was not due to the microwave signal saturation. As it comes out from this paper, positions of $\mathrm{P}_{\mathrm{Ga}} \mathrm{P}_{4}$ and WA1 paramagnetic levels are very close to each other in GaP energy gap. In order to estimate populations of electrons at such close 
levels it seems reasonable to take into account changes of electron number with temperature increase described by both the Boltzmann dependence (usually used in ESR) and the Fermi-Dirac statistics. Calculations performed in the presented paper showed that the Fermi level position between defect levels caused gradual evacuation of the lower level, $\mathrm{Ga}_{\mathrm{p}}^{-10}$, and gradual filling of the upper level, $\mathrm{P}_{\mathrm{Ga}}^{+/++}$, with temperature increase. Fitting to the experimental results for the Fermi level at $1.229 \mathrm{eV}$ above the valence band is presented in Fig. 2b. Quite well agreement for signals of both paramagnetic defects in n-irradiated $\mathrm{GaP}$ was obtained.

In summary, the position of paramagnetic gallium antisite level in $\mathrm{GaP}$ energy gap was determined and the position of phosphorus antisite level determined in [5] was confirmed. Moreover, the unusual, in ESR experiments, temperature dependence of $\mathrm{P}_{\mathrm{Ga}} \mathrm{P}_{4}$ amplitude in n-irradiated $\mathrm{GaP}$ crystals observed in $[1,3]$ was explained.

\section{References}

[1] J. Jasiński, M. Palczewska, K. Korona, M. Kamińska, E.D. Bourret, G. Elliot, Acta Phys. Pol. A 82, 829 (1992).

[2] J. Kruger, H. Alexander, Mater. Sci. Forum 83-87, 899 (1992).

[3] J. Jasiński, M. Kamińska, M. Palczewska, E. Jurkiewicz-Wegner, Acta Phys. Pol. A 84, 579 (1993).

[4] R. Worner, U. Kaufman, J. Schneider, Appl. Phys. Lett. 40, 141 (1982).

[5] U. Kaufmann, J. Schneider, R. Worner, T.A. Kennedy, N.D. Wilsey, J. Phys. C 14, L951 (1981). 